\title{
THE
}

\section{DNA Sequence Mediates Apparent Length Distribution in Single- Walled Carbon Nanotubes}

\author{
Mohammad Moein Safaee \\ University of Rhode Island \\ Mitchell Gravely \\ University of Rhode Island \\ Caroline Rocchio \\ University of Rhode Island \\ Matthew Simmeth \\ University of Rhode Island \\ Follow this and additional works at: https://digitalcommons.uri.edu/che_facpubs \\ OnjeltEof Rpxpury \\ Univarnitu a Dhodn Inland rovhurvaurind. \\ The University of Rhode Island Faculty have made this article openly available. \\ Please let us know how Open Access to this research benefits you.
}

This is a pre-publication author manuscript of the final, published article.

Terms of Use

This article is made available under the terms and conditions applicable towards Open Access Policy Articles, as set forth in our Terms of Use.

\section{Citation/Publisher Attribution}

Safaee, M. M., Gravely, M., Rocchio, C., Simmeth, M., \& Roxbury, D. (2018). DNA Sequence Mediates Apparent Length Distribution in Single-Walled Carbon Nanotubes. ACS Appl. Mater. Interfaces, 11(2), 2225-2233. doi: $10.1021 /$ acsami.8b16478

Available at: http://dx.doi.org/10.1021/acsami.8b16478 


\title{
DNA Sequence Mediates Apparent Length
}

\section{Distribution in Single-Walled Carbon Nanotubes}

\author{
Mohammad Moein Safaee ${ }^{1}$, Mitchell Gravely ${ }^{1}$, Caroline Rocchio ${ }^{1}$, Matthew Simmeth $^{1}$, \\ Daniel Roxbury ${ }^{1^{*}}$ \\ ${ }^{1}$ Department of Chemical Engineering, University of Rhode Island, Kingston, Rhode Island \\ 02881, United States
}

KEYWORDS. nanotechnology, atomic force microscopy, DNA functionalized single-walled carbon nanotubes, biosensing, bioimaging

\begin{abstract}
Single-walled carbon nanotubes (SWCNTs) functionalized with short single-stranded DNA have been extensively studied within the last decade for biomedical applications due to the high dispersion efficiency and intrinsic biocompatibility of DNA as well as the photostable and tunable fluorescence of SWCNTs. Characterization of their physical properties, particularly their length distribution, is of great importance regarding their application as a bioengineered research tool and clinical diagnostic agent. Conventionally, atomic force microscopy (AFM) has been used to quantify the length of DNA-SWCNTs by depositing the hybrids onto an electrostatically charged flat surface. Here, we demonstrate that hybrids of DNA-SWCNTs with different oligomeric DNA sequences $\left((\mathrm{GT})_{6}\right.$ and $\left.(\mathrm{GT})_{30}\right)$ differentially deposit on the AFM substrate, resulting in significant
\end{abstract}


inaccuracies in the reported length distributions of the parent solutions. Using a solution-based surfactant exchange technique, we placed both samples into a common surfactant wrapping and found identical SWCNT length distributions upon surface deposition. Additionally, by spincoating the surfactant wrapped SWCNTs onto a substrate, thus mitigating effects of electrostatic interactions, we found length distributions that did not depend on DNA sequence but were significantly longer than electrostatic deposition methods, illuminating the inherent bias of the surface deposition method. Quantifying the coverage of DNA molecules on each SWCNT through both absorbance spectroscopy and direct observation, we found that the density of DNA per SWCNT was significantly higher in short $(\mathrm{GT})_{6}$-SWCNTs (length $<100 \mathrm{~nm}$ ) compared to long (GT)6-SWCNTs (length $>100 \mathrm{~nm}$ ). In contrast, we found no dependence of the DNA density on SWCNT length in (GT) $)_{30}$-SWCNT hybrids. Thus, we attribute differences in the observed length distributions of DNA-SWCNTs to variations in electrostatic repulsion induced by sequencedependent DNA density. 


\section{Introduction}

Single-walled carbon nanotubes (SWCNTs) with engineered wrappings ${ }^{1-4}$ have recently been developed and utilized in various disparate fields ranging from additives that strengthen material $\operatorname{composites}^{5-8}$ to biomedical applications including targeted anti-cancer drug delivery ${ }^{9-11}$, nearinfrared (NIR) optical biosensing, ${ }^{12-14}$ and biological imaging. ${ }^{15-18}$ Of significant interest, SWCNTs exhibit intrinsic photoluminescence (fluorescence) that is photostable, tunable, and sensitive to its local environment. ${ }^{19-20}$ Unfortunately, covalent functionalization is known to negatively affect SWCNT electrical and optical properties, ${ }^{21}$ thus, alternative non-covalent methods are preferred. Certain amphiphilic biomolecules such as DNA, $,{ }^{4}, 14,22$ peptides, ${ }^{23-24}$ proteins, ${ }^{25-26}$ or lipids, ${ }^{27-28}$ have been shown to effectively solubilize SWCNTs, in addition to imparting enhanced biocompatibility and preserving their desirable fluorescence by noncovalently adsorbing onto the aromatic sidewall of the SWCNT. ${ }^{29}$

Having both hydrophobic bases and a hydrophilic backbone, single-stranded DNA has been demonstrated to non-covalently attach to the outside of the SWCNTs by hydrophobic and $\pi-\pi$ stacking interactions and act as a highly-effective dispersant for SWCNTs. ${ }^{4}$ This dispersion process generally involves probe-tip sonication to impart enough energy in order to break up initially bundled SWCNTs ${ }^{29}$ with the off-target effect of cutting the SWCNTs to random lengths. ${ }^{30}$ Both empirical studies ${ }^{31-32}$ and molecular dynamics simulations ${ }^{33}$ have shown that DNA helically wraps the SWCNTs in aqueous solution, and further that this structure is preserved when the DNASWCNT hybrid is dried onto a surface. ${ }^{34}$ Interestingly, while longer oligonucleotides have a stronger binding affinity to SWCNTs, as probed through absorption spectroscopy, atomic force microscopy, nanoparticle fluorescence spectroscopy and molecular dynamics simulations, certain short sequences of DNA recognize specific chiralities of SWCNTs and permit their separation from an ensemble solution. ${ }^{35}$ 
There have been many recent studies demonstrating the utilization of DNA-SWCNT hybrids in biomedical applications. ${ }^{12-14,28,36-38}$ Critical to their adoption as a standard biological research tool is a thorough characterization of their physical properties, namely their length distribution. The length of a SWCNT directly correlates to its photoluminescence (fluorescence) intensity. ${ }^{39}$ For biological imaging and sensing applications, quantitative measurements rely on accurate determinations of the SWCNT length. For example, DNA-wrapped SWCNTs have recently been introduced as intracellular sensors of lipid accumulation both in live cells ${ }^{13}$ and in mice. ${ }^{40}$ In the development of these and other types of SWCNT-based sensors, accurate length determinations of SWCNTs provide the most precise quantification of targeted analytes. Further, the toxicological response of SWCNTs can be more accurately predicted given knowledge of their average length and length distribution..$^{41-42}$

The conventional method for determining the length distribution of a population of DNASWCNTs is to deposit the hybrids onto an atomically flat surface, e.g. freshly cleaved mica, and image them with atomic force microscopy (AFM) techniques. ${ }^{4}$ However, it is unknown whether this adsorbed fraction of DNA-SWCNTs is representative of the entire solution sample. A search of the literature has uncovered $\sim 20$ publications within the last decade that have used this particular approach for length determination. ${ }^{4}, 34,41,43-57$ Herein, we demonstrate that the apparent length distribution of DNA-SWCNTs, as determined by conventional AFM imaging techniques, is highly dependent upon the sequence of DNA that is used to wrap the SWCNTs. In particular, under identical sample preparation conditions, oligomeric DNA with two different sequence lengths, $(\mathrm{GT})_{6}$ and $(\mathrm{GT})_{30}$, gave apparent length distributions of $150 \pm 8$ and $67 \pm 7 \mathrm{~nm}$, respectively. By transferring the hybrids into a common wrapping through the use of sodium deoxycholate (SDC)induced DNA displacement, we show that the length distributions of the two samples converge to a statistically identical value. Spin-coating of these samples onto a substrate, thereby reducing the 
electrostatic interactions between the SWCNTs and the substrate, gave length distributions that did not depend on DNA sequence, but were longer than electrostatically deposited samples. Furthermore, by quantifying the number of DNA sequences on the individual SWCNTs, we found that shorter $(\mathrm{GT})_{6}$-SWCNTs (length $<100 \mathrm{~nm}$ ) displayed significantly higher densities of DNA than any other sub-population of examined DNA-SWCNTs. Finally, we quantified the exact weights of DNA and SWCNT in each sample with absorbance spectroscopy and propose a model to explain the differential rates of binding to the AFM imaging surface that depend on SWCNT length and DNA loading.

\section{Results and Discussion}

Singly-dispersed hybrids of SWCNTs and single-stranded (GT)6, i.e. GTGTGTGTGTGT, or $\mathrm{ss}(\mathrm{GT})_{30}$ were prepared by previously reported sonication and ultracentrifugation techniques. ${ }^{20} \mathrm{In}$ order to determine the length distribution of each sample, a solution of DNA-SWCNTs was exposed to an ultra-flat surface (freshly-cleaved mica) for 4 minutes (herein referred to as "deposited"), the surface was washed, and then imaged with an atomic force microscope. Figures 1a,b show representative AFM images obtained from (GT) $)_{6}$-SWCNTs or (GT) ${ }_{30}$-SWCNTs, respectively. From initial inspection of the images, it is clear that the length distribution of deposited SWCNTs was larger in the $(\mathrm{GT})_{6}$ sample than that of $(\mathrm{GT})_{30}$. To quantify the difference, manual counting of the SWCNT lengths was performed on 1600 SWCNTs from each sample. The derived length distributions are presented in Figures 1c and S1a and confirm that the distribution for $(\mathrm{GT})_{6}$-SWCNTs was shifted to longer SWCNT lengths compared to that of the (GT) ${ }_{30}$-SWCNT distribution. Furthermore, the average SWCNT lengths from each of four AFM images per sample, each image containing 400 SWCNTs, were compared. These data are presented in Figure 1d and show that the average length of deposited (GT)6-SWCNTs and (GT) $)_{30-}$ 
SWCNTs were $150 \pm 8$ and $67 \pm 7$, respectively (Figure S2a shows the data from four images combined together). This difference demonstrates that deposited (GT)6-SWCNTs were significantly longer (two-sample t-test, $\mathrm{p}<0.001$ ) than deposited $(\mathrm{GT})_{30}$-SWCNTs.

a)

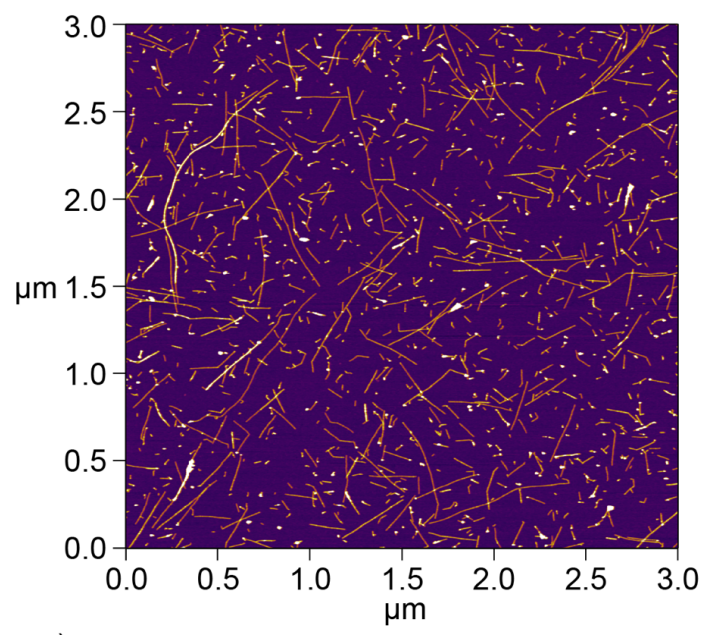

c)

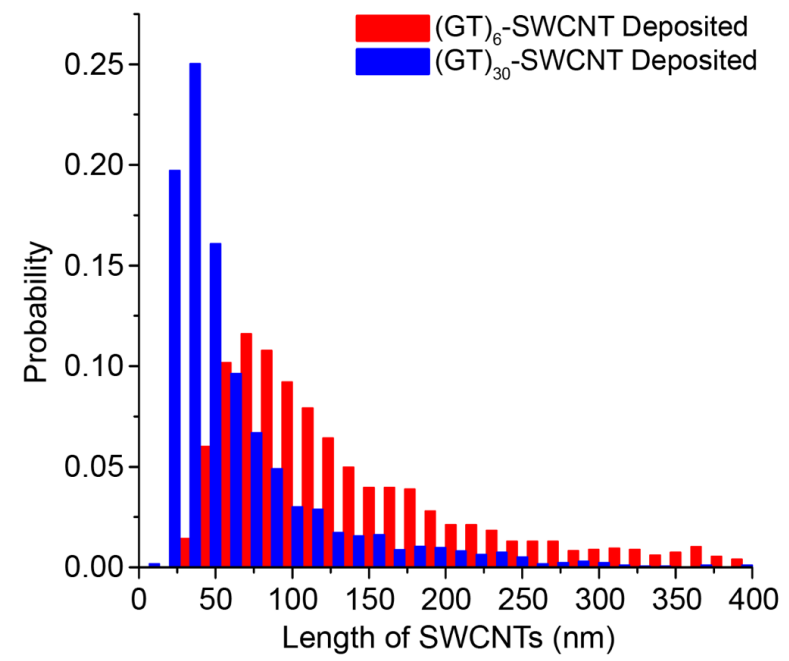

b)

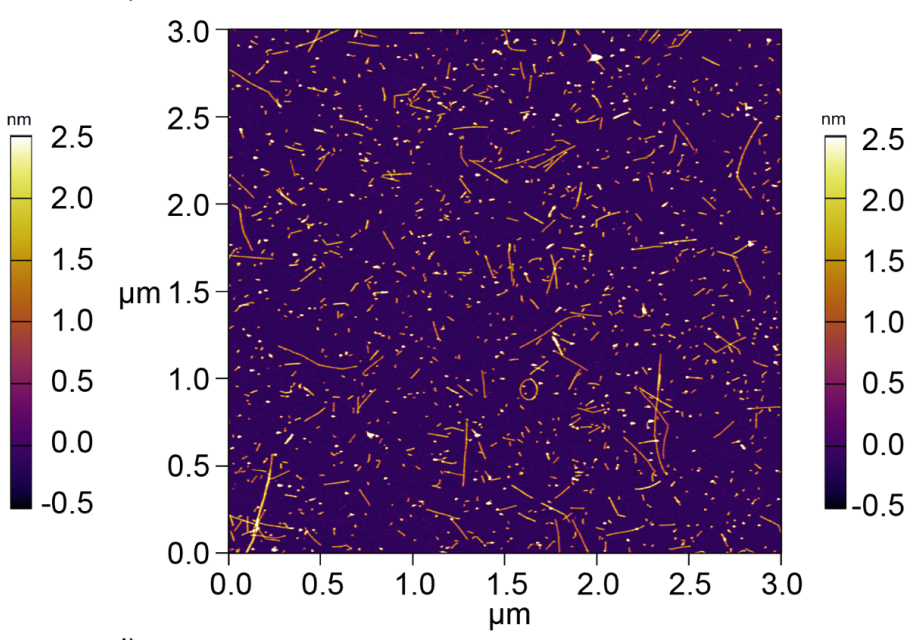

d)

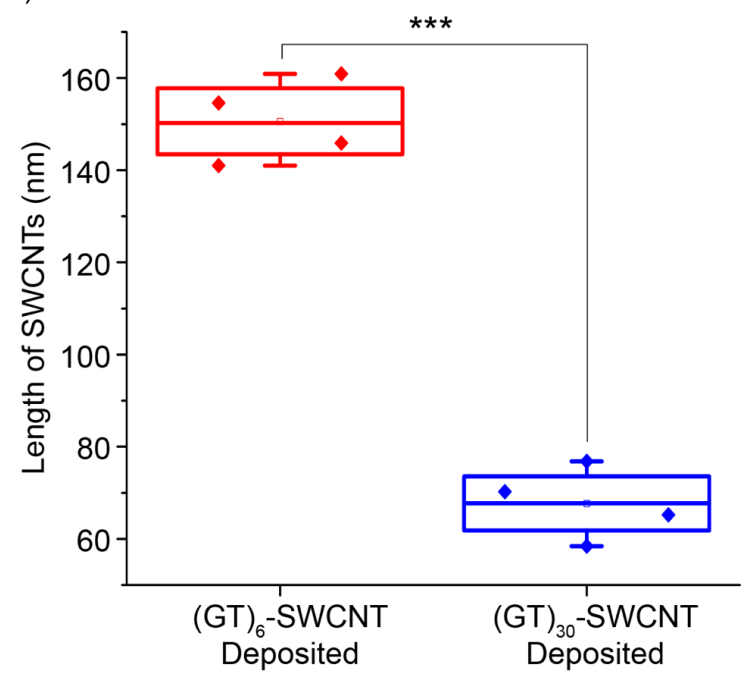

Figure 1. DNA-SWCNTs deposited onto mica. AFM images of (a) (GT) 6 -SWCNTs and (b) (GT) ${ }_{30}$-SWCNTs. (c) Histograms for length distributions of (GT) ${ }_{6}-\mathrm{SWCNTs}$ and $(\mathrm{GT})_{30^{-}}$ SWCNTs. (d) The corresponding box and whisker plots to compare the average SWCNT lengths from each of four AFM images per sample for $(\mathrm{GT})_{6}-\mathrm{SWCNTs}$ and $(\mathrm{GT})_{30}$-SWCNTs. The boxes represent the minimum, maximum, and mean values from $n=4$ images, each image containing 400 DNA-SWCNTs. The whiskers represent 25-75 percentile data. A two-sample t-test was performed on the image-averaged data $(* * *, \mathrm{p}<0.001)$.

The previous result regarding apparent length distributions of DNA-SWCNTs that depended upon DNA sequence gave rise to one of two hypotheses: 1) the two samples were intrinsically 
different and that the length distributions of deposited DNA-SWCNTs were representative of the parent solutions or 2) the differing DNA sequences introduced an artifact in the binding process leading to length distributions that differed from the parent solutions. To identify the cause of the sequence-dependent difference in apparent lengths, we used a solution-based surfactant exchange technique that displaced the DNA from the two samples and placed them both into a common surfactant wrapping. ${ }^{20}$ Similar to the DNA-SWCNT samples, the two DNA-displaced SDCSWCNT samples, denoted as $(\mathrm{GT})_{6}$ to SDC and $(\mathrm{GT})_{30}$ to SDC, were deposited onto mica and imaged with AFM (Figure 2a,b). The displacement of DNA by SDC is confirmed both by blueshifts in the near-infrared absorbance peaks of the SWCNTs ${ }^{35}$ (Figure S3) and by the irregular pattern of SDC molecules on the SWCNTs in contrast to the regular pattern (helical wrapping) of DNA on the SWCNTs. ${ }^{34}$ Despite an increased background height, presumably due to excess surfactant bound to the mica, it is visually evident that the two samples had similar distributions of SWCNT lengths. The length measurements for DNA-displaced SDC-SWCNTs, presented as overall length distributions (Figure 2c, S1b) and image-averaged data (Figure 2d), each image containing $\sim 150$ SWCNTs, confirm the lack of significant difference (two-sample t-test) between the two surface-bound SDC-SWCNT samples (Figure S2b presents the data from four images combined together). The data affirm the hypothesis that the apparent length distributions of deposited SWCNTs are influenced by both DNA sequence and wrapping type, i.e. DNA vs. surfactant (Figure 2e,f).

It has been reported by Weisman et al. that AFM imaging of spin-coated SWCNTs dispersed in surfactant accurately represents the solution phase in terms of SWCNT lengths, since all SWCNTs from the parent sample are placed onto the substrate. ${ }^{58}$ Therefore, we repeated length characterizations of DNA-displaced SDC-SWCNT samples that were spin-coated onto precleaned silicon wafers (Figure S4). Despite this alternative method of placing SWCNTs on a 
surface, we observed no significant dependence on DNA sequence (Figure S4a-d). Notably, we observe significant increases in mean SWCNT lengths compared to deposited DNA-displaced SDC-SWCNTs (Figure S4e,f). We hypothesize that the increases stem from mitigating the electrostatic interactions between the SWCNTs and the substrates, thereby yielding more accurate length distributions.
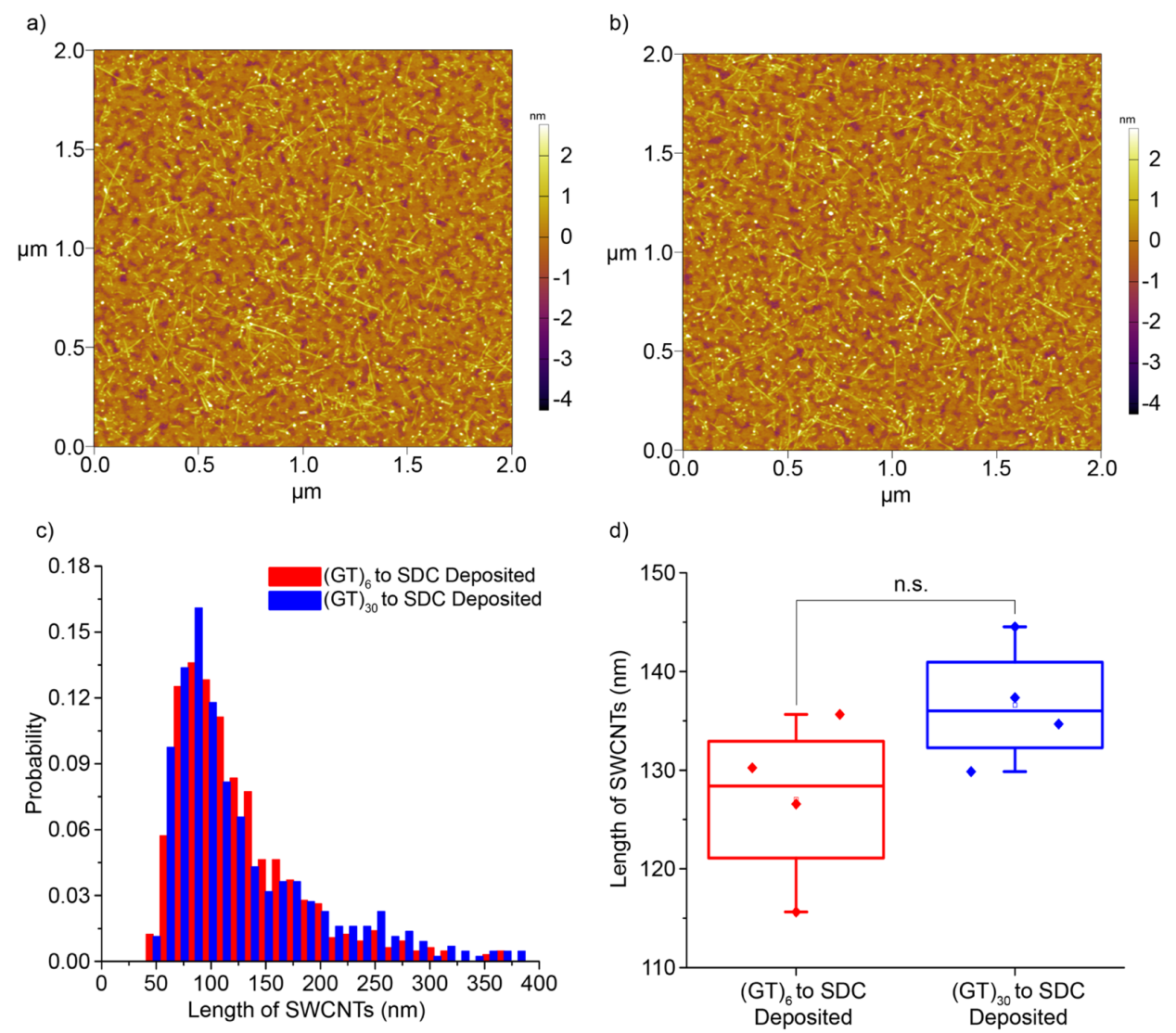

d)
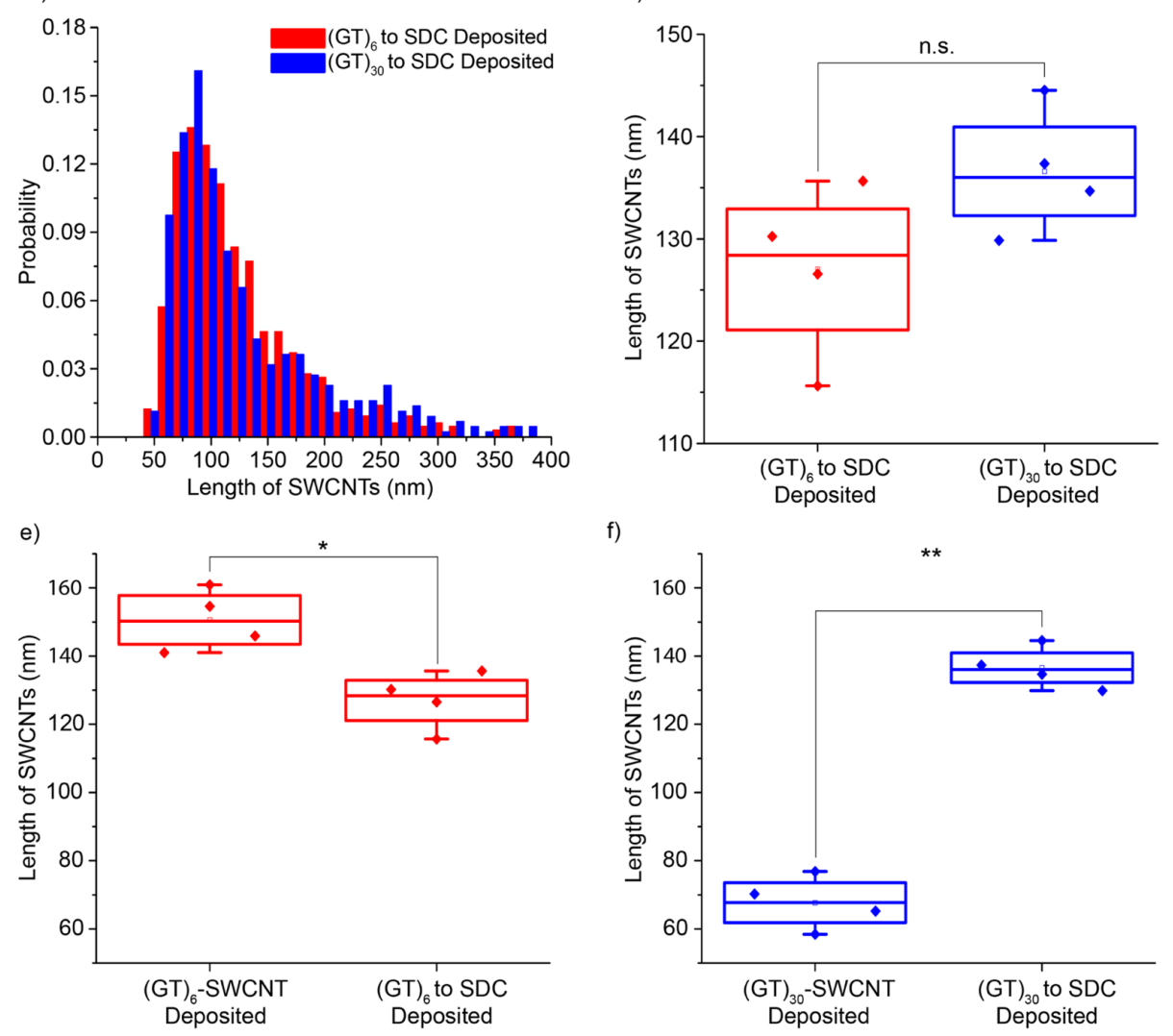

Figure 2. DNA-displaced SDC-SWCNTs deposited onto mica. AFM images of (a) (GT)6displaced SDC-SWCNTs and (b) (GT) ${ }_{30}$-displaced SDC-SWCNTs. (c) Histograms for length 
distributions of (GT) 6 -displaced SDC-SWCNTs $\left((\mathrm{GT})_{6}\right.$ to SDC) and $(\mathrm{GT})_{30}$-displaced SDCSWCNTs ((GT) ${ }_{30}$ to SDC). (d) The corresponding box and whisker plots to compare the average SWCNT lengths from each of four AFM images per sample for (GT) $)_{6}$-displaced SDC-SWCNTs and (GT) $)_{30}$-displaced SDC-SWCNTs. The boxes represent the minimum, maximum, and mean values from $\mathrm{n}=4$ images, each image containing $\sim 150$ SDC-SWCNTs. The whiskers represent 25 75 percentile data. Box and whisker plots to compare the average SWCNT lengths from each of four AFM images per sample for (e) (GT) ${ }_{6}$-SWCNTs and (GT) ${ }_{6}$-displaced SDC-SWCNTs, and (f) (GT) $)_{30}$-SWCNTs and (GT) $)_{30}$-displaced SDC-SWCNTs. The boxes represent the minimum, maximum, and mean values from $\mathrm{n}=4$ images. The whiskers represent $25-75$ percentile data. A two-sample t-test was performed on the image-averaged data $(*, \mathrm{p}<0.05, * *, \mathrm{p}<0.01)$.

To explain the difference in length distributions of deposited DNA-SWCNTs, we hypothesize that differential interactions exist between SWCNTs and DNA of varying sequence and further that these interactions mediate the process of surface adsorption. We examined the height profiles along single SWCNTs in higher resolution AFM images in order to quantify the coverage from DNA molecules interacting with individual SWCNTs (Figure 3a,b for representative (GT)6SWCNT and Figure 3c,d for representative (GT) $)_{30}$-SWCNT). As demonstrated previously, ${ }^{34}$ the absolute number of DNA molecules and the density of DNA coverage on each SWCNT was quantified by counting the peaks in the height profiles. It is worth noting that each peak in DNASWCNT height profile could arise from either each turn of helically wrapped DNA around the SWCNT or each DNA molecule on the SWCNT, depending on the length of the DNA strand. ${ }^{34}$ The number of turns made by a single DNA around a single SWCNT can be calculated by assuming that rolling a rectangle, so that its diagonal (of length 1) makes exactly one helical turn, forms a cylinder which can be wrapped with one helical turn of DNA. The length of the diagonal (l) can be calculated from Pythagorean Theorem ${ }^{34}: l=\sqrt{h^{2}+(\pi d)^{2}}$, where $h$ is the average peak to peak distance quantified from high resolution AFM images (Figure S5a,b) and d is the average diameter of HiPco SWCNTs $(1.1 \mathrm{~nm}) .{ }^{59}$ The total length of the stretched DNA molecule (L) is number of its turns around the SWCNT (n) times $1(\mathrm{~L}=\mathrm{nl})$. "L" is calculated by assuming a distance of $0.7 \mathrm{~nm}$ between phosphorus atoms on the DNA backbone ( $\mathrm{L}$ is $8.4 \mathrm{~nm}$ for a $12 \mathrm{mer}$ ). ${ }^{34}$ 
Thus, the number of the turns made by a single DNA around a single SWCNT was calculated to be 0.6 and 2.8 for $(\mathrm{GT})_{6}$-SWCNTs and (GT) $)_{30}$-SWCNTs, respectively. These numbers imply that the $(\mathrm{GT})_{6}$ strand is not long enough to have a complete turn and shows up as a single peak in the height profiles whereas (GT) ${ }_{30}$ makes two complete turns and one partial turn around the SWCNTs, and appears as three peaks per each molecule in the height profiles.

a)

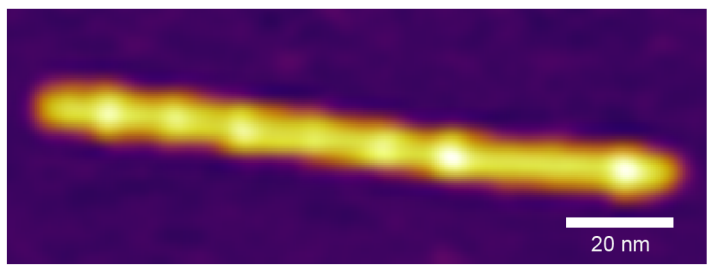

c)

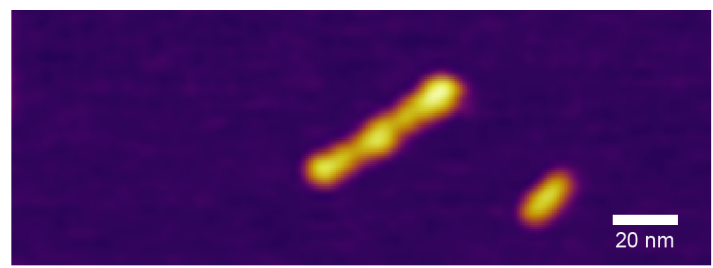

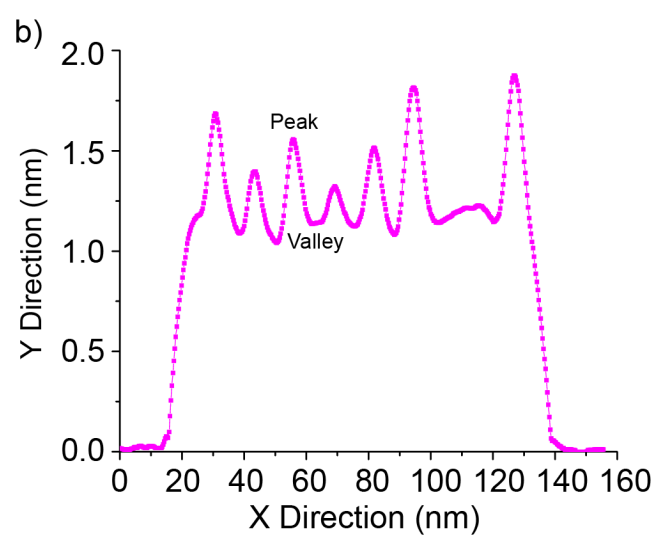

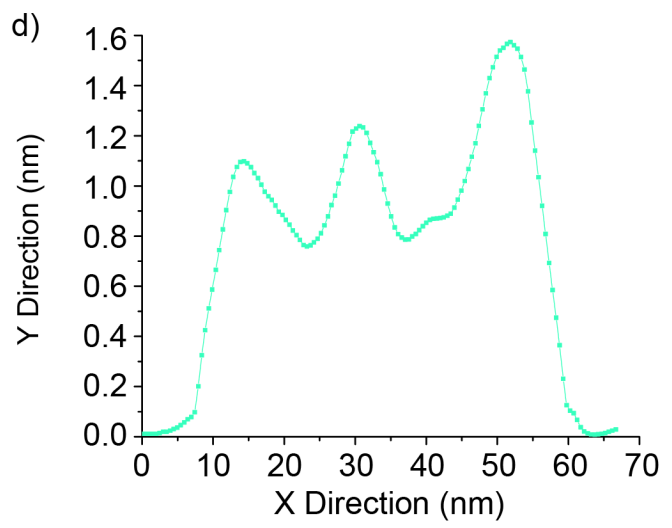

Figure 3. Height profiles along the representative individual SWCNTs. (a) and (b) (GT) ${ }_{6}$-SWCNT. (c) and (d) (GT) $)_{30}$-SWCNT. Each bright spot on the SWCNT represents a peak in the height profile.

We plotted the number of the peaks versus length of each examined SWCNT in the two samples (Figure 4a). Positive linear correlations between the number of the peaks and SWCNT length were observed (Pearson correlation coefficients of 0.832 and 0.889 for $(\mathrm{GT})_{6}$-SWCNTs and $(\mathrm{GT})_{30^{-}}$ SWCNTs, respectively), suggesting a consistent density of DNA along the SWCNT. A single ratiometric parameter could be derived for each DNA-SWCNT by dividing the number of the 
peaks by the length of the SWCNT, i.e. [count / nm], as a measure for the DNA density on the SWCNT side-wall. Denoted herein as "N/L", we present total N/L distributions in Figure 4b, and image-averaged N/L data (each image containing 16 data) in Figure 4c (Figure S2d demonstrates the data from four images combined together). On average, the surface coverage of DNA on SWCNTs is significantly higher $(\mathrm{p}<0.01)$ in $(\mathrm{GT})_{6}$-SWCNTs than that of $(\mathrm{GT})_{30}$-SWCNTs.

a)

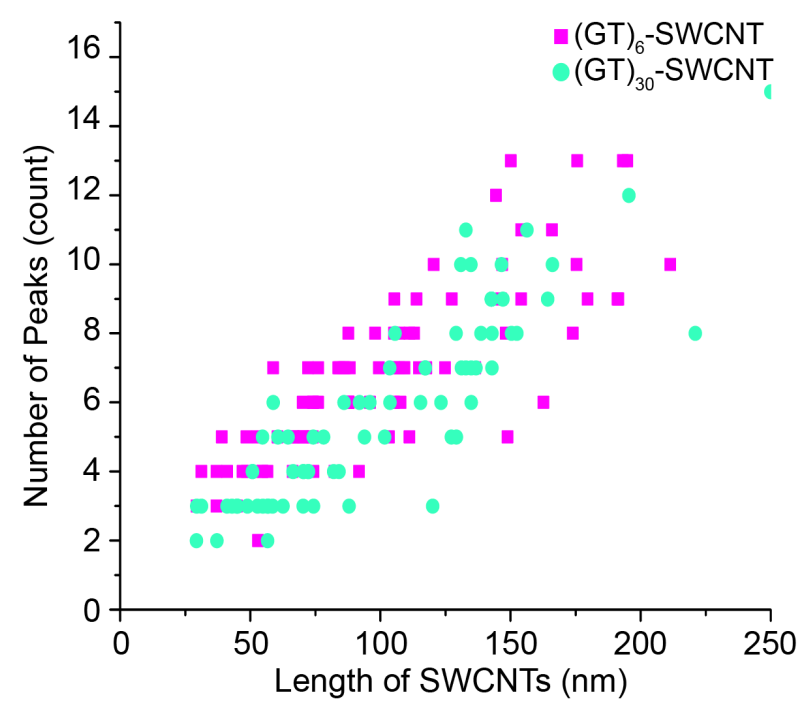

b)

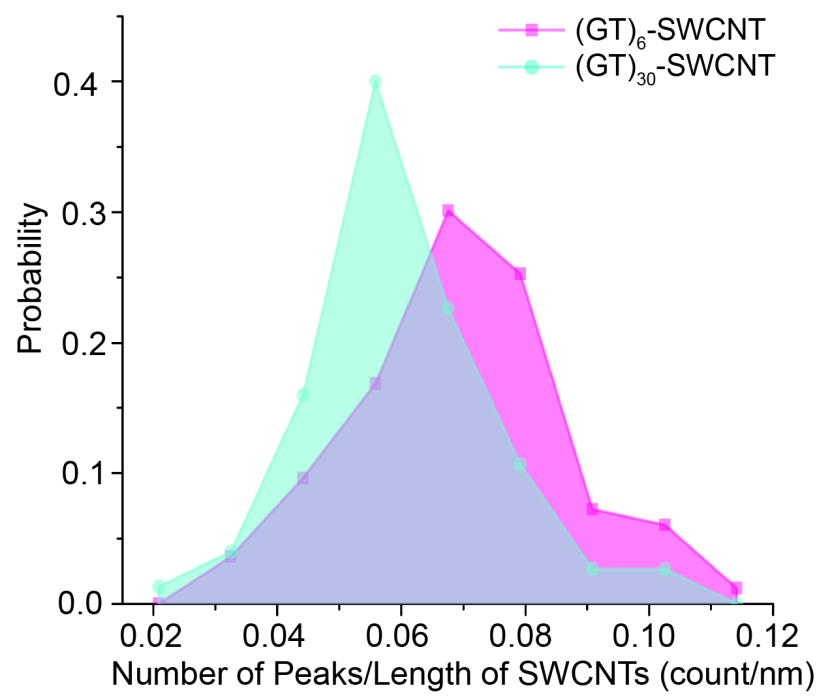

c)

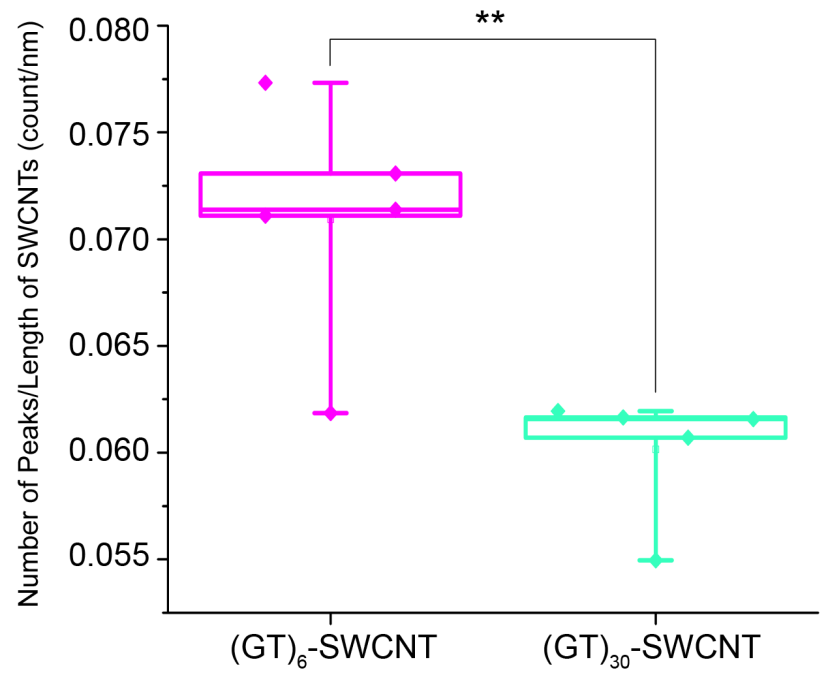

Figure 4. (a) Number of peaks on single SWCNT versus length of each SWCNT in $(\mathrm{GT})_{6^{-}}$ SWCNTs and (GT) ${ }_{30}$-SWCNTs, (b) Overlaid histograms for the distribution of N/L for (GT) 6- $^{-}$

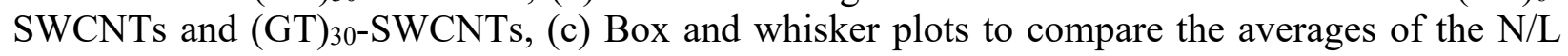
ratios obtained from five images for each sample. The boxes represent the minimum, maximum, and mean values from $n=5$ images, each image containing $\sim 16$ SWCNTs. The whiskers represent 
25-75 percentile data. Two-sample t-tests were performed on the image-averaged data (**, $\mathrm{p}<0.01)$.

To confirm this finding of differential DNA coverage from the AFM images, we quantified the actual weights of DNA and SWCNTs in aqueous samples using absorbance spectroscopy and the previously utilized surfactant exchange method. Using extinction coefficients for DNA and SWCNTs at $260 \mathrm{~nm}^{60}$ and $910 \mathrm{~nm},{ }^{61}$ respectively, the absolute weights were determined and the weight ratios of DNA to SWCNT are reported in Figure 5. This ratio in (GT) 6 -SWCNT sample is significantly higher than that of (GT) $)_{30}$-SWCNT, confirming the finding from comparing the N/L of the two samples.

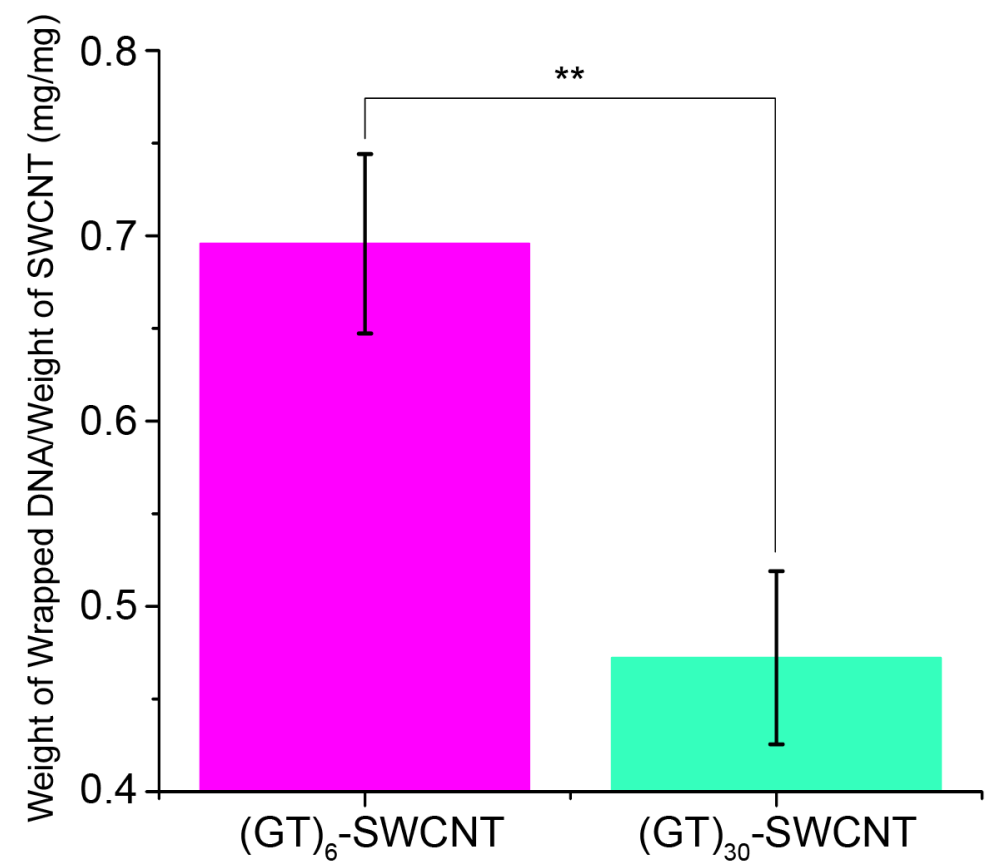

Figure 5. The ratio of the total weight of wrapped DNA to weight of SWCNTs in solutions of $(\mathrm{GT})_{6}$-SWCNT and $(\mathrm{GT})_{30}$-SWCNT. Mean values were obtained from $\mathrm{n}=3$ measurements per sample. Two-sample t-tests were performed on the data $(* *, p<0.01)$.

Upon closer inspection of the scatterplots found in Figure 4a, we detect distinct subpopulations in the data. By dividing the data into two populations distinguished by the length of the SWCNTs, e.g. SWCNTs greater than or less than $100 \mathrm{~nm}$, respectively, we uncovered significant differences 
in the density of DNA per SWCNT (Figure 6). While we found no dependence of the N/L ratios on SWCNT length in $(\mathrm{GT})_{30}$-SWCNT hybrids, we observed that $(\mathrm{GT})_{6}$-SWCNTs with lengths less than $100 \mathrm{~nm}$ have an average of $27 \%$ higher DNA density $(\mathrm{p}<0.01)$.

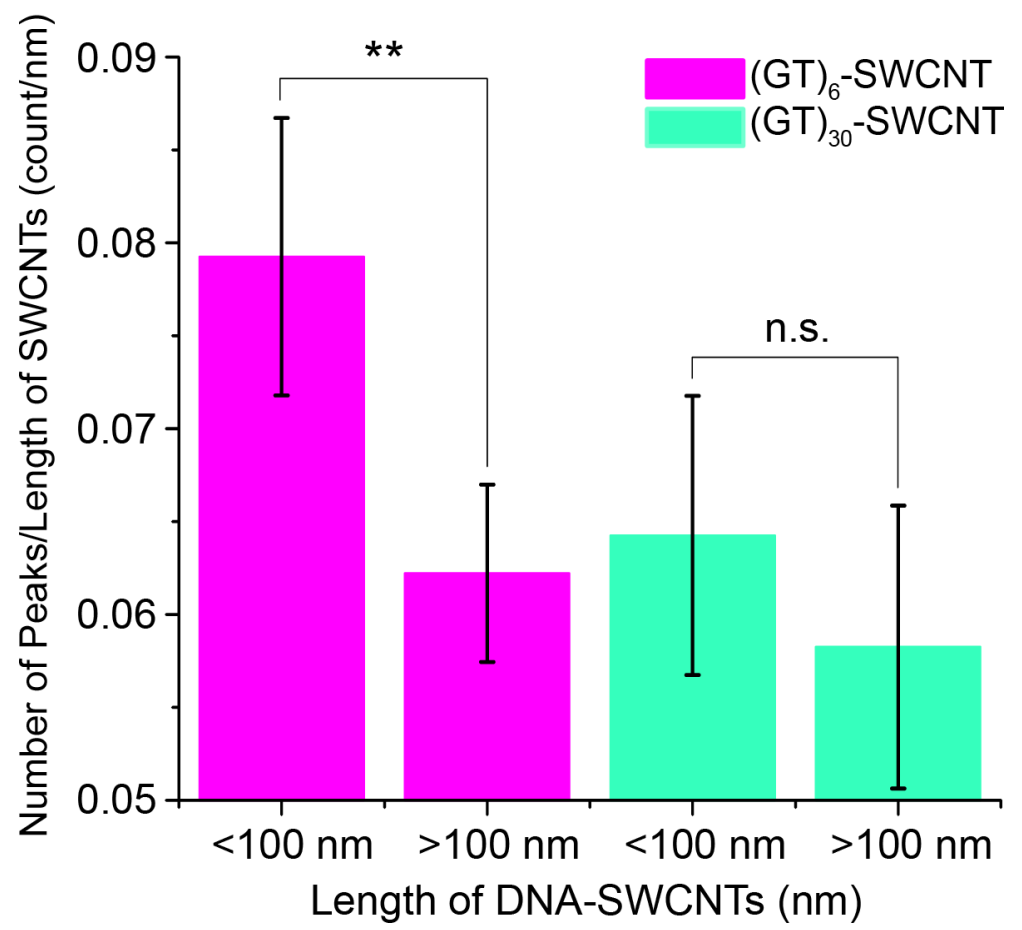

Figure 6. N/L ratios for two subgroups distinguished by the length of the SWCNTs (Length $<100$ $\mathrm{nm}$ and Length $>100 \mathrm{~nm}$ ) for $(\mathrm{GT})_{6}$-SWCNTs and (GT) ${ }_{30}$-SWCNTs.

We believe that this result endorses the DNA sequence-dependent discrepancies of length distributions in deposited DNA-SWCNTs due to the following mechanism: with permanent negative charges at neutral $\mathrm{pH}$, non-covalent complexation of DNA with SWCNTs results in a negatively charged hybrid with charge density that scales with DNA density ( $\mathrm{N} / \mathrm{L}$ ratio). As a result, the electrostatic repulsion between the negatively charged AFM substrate (mica) and shorter (GT) ${ }_{6}$-SWCNTs (length $<100 \mathrm{~nm}$ ) in water is significantly larger than that of the substrate and longer $(\mathrm{GT})_{6}$-SWCNTs (length $>100 \mathrm{~nm}$ ). The longer $(\mathrm{GT})_{6}$-SWCNTs subsequently bind to the AFM substrate at a faster rate compared to shorter $(\mathrm{GT})_{6}$-SWCNTs within the limited time interval

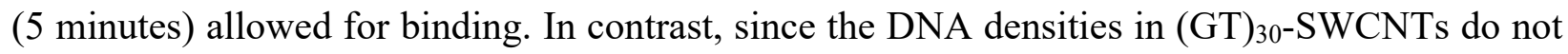


depend on the SWCNT length, the electrostatic repulsion between short and long (GT) $)_{30}$-SWCNTs and the AFM substrate will be similar. Here, we propose that the shorter (GT) ${ }_{30}$-SWCNTs will bind to the AFM substrate with a faster rate due to their intrinsically higher diffusion coefficients. ${ }^{58}$ A schematic illustrating this differential binding process is presented in Figure 7. We emphasize the difference between DNA density on SWCNT, and the number of the turns of each DNA molecule around SWCNT.

a)

$(\mathrm{GT})_{6}$-SWCNT

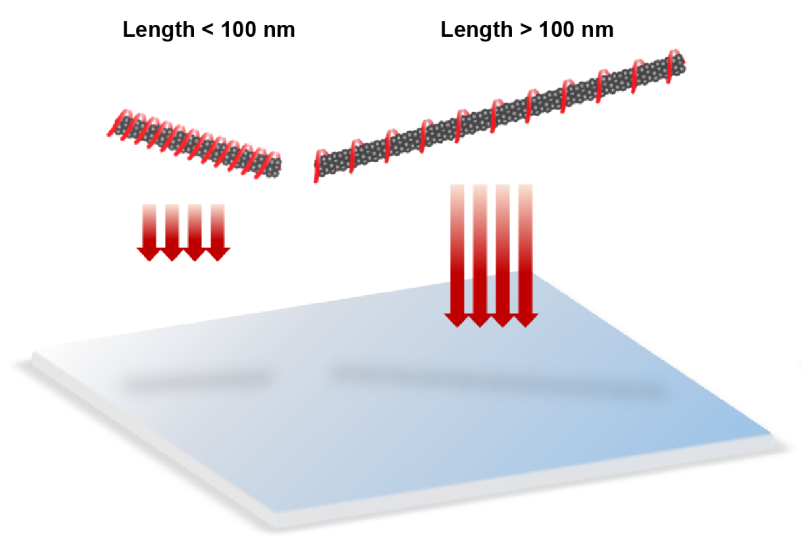

b)

$(\mathrm{GT})_{30}$-SWCNT

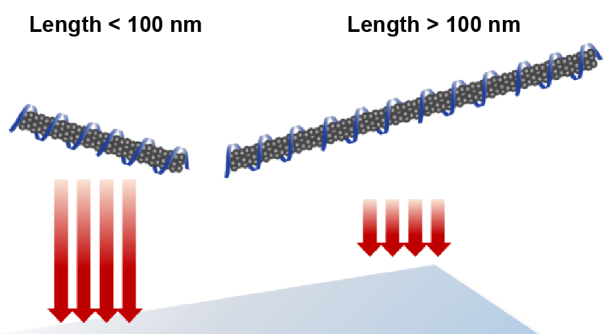

Figure 7. Illustration of the differential binding process of DNA functionalized SWCNTs on mica substrates. (a) Short (GT) ${ }_{6}$-SWCNTs have higher DNA density compared to long (GT)6SWCNTs. This causes stronger electrostatic repulsion between short (GT)6-SWCNTs and the negatively charged substrate, leading to higher fraction of long (GT) ${ }_{6}-\mathrm{SWCNT}$ s binding. (b) DNA density on short and long $(\mathrm{GT})_{30}$-SWCNTs is the same. Increased binding of short $(\mathrm{GT})_{30^{-}}$

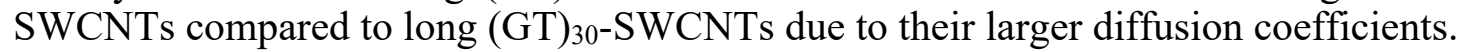

\section{Conclusions}

In this study, we have shown that hybrids of DNA and SWCNTs will differentially bind to a conventional AFM imaging substrate (freshly-cleaved mica) in a manner that significantly depends upon the sequence of DNA. By displacing the DNA from the SWCNTs, we have shown that the length distributions of the resulting surfactant-coated SWCNTs are statistically identical. Spincoating of these DNA-displaced samples results in larger length distributions that still do not depend on DNA sequence. Therefore, we surmise that the DNA mediates the interactions between 
the DNA-SWCNT hybrids and the imaging substrate. By quantifying the weight and coverage of DNA molecules on each SWCNT, we find that $(\mathrm{GT})_{6}$ binds with a higher density to shorter SWCNTs and that this difference between DNA sequences can explain the observed discrepancies in apparent length distributions of the surface-bound samples. Finally, we propose that for accurate length determinations of SWCNT samples through AFM measurements, DNA-SWCNTs should be transferred to a surfactant wrapping prior to surface adsorption through a spin-coating method.

\section{Materials and Methods}

DNA-SWCNT Sample Preparation: Single-walled carbon nanotubes produced by the HiPco process (Nanointegris) were used throughout the study. For each dispersion, $1 \mathrm{mg}$ of raw nanotubes was added to $2 \mathrm{mg}$ of desalted $(\mathrm{GT})_{\mathrm{n}}(\mathrm{n}=6$ or 30$)$ oligonucleotide (Integrated DNA Technologies) in a microcentrifuge tube with $1 \mathrm{~mL}$ of $100 \mathrm{mM} \mathrm{NaCl}$ (Sigma-Aldrich). The mixtures were then ultrasonicated using a 1/8" tapered microtip (Sonics Vibracell; Sonics \& Materials) for $30 \mathrm{~min}$ at $40 \%$ amplitude, with an average power output of $8 \mathrm{~W}$, in a $0{ }^{\circ} \mathrm{C}$ temperature-controlled microcentrifuge tube holder. After sonication, the dispersion was ultracentrifuged (Sorvall Discovery M120 SE) for $30 \mathrm{~min}$ at 250,000 $\mathrm{xg}$, and the top $80 \%$ of the supernatant was extracted. The concentration was determined with a UV/vis/NIR spectrophotometer (Jasco, Tokyo, Japan), using the extinction coefficient of $A_{910}=0.02554^{38,61-}$

${ }^{62} \mathrm{~L} \cdot \mathrm{mg}^{-1} \cdot \mathrm{cm}^{-1}$. The free DNA was removed using $100 \mathrm{kDa}$ Amicon centrifuge filters (Millipore). For each sample, filtration was repeated 4 times and the pellet was resuspended in $100 \mathrm{mM} \mathrm{NaCl}$ in each step. The resultant suspensions were used for concentration measurement and diluted in $100 \mathrm{mM} \mathrm{NaCl}$ to reach the final DNA-SWCNT concentration of $20 \mathrm{mg} / \mathrm{L}$ and used for further AFM imaging and DNA quantification. 
Surfactant Displacement of DNA: The resultant filtered suspensions of DNA-SWCNTs were diluted in $100 \mathrm{mM} \mathrm{NaCl}+0.1 \mathrm{wt} \% \mathrm{SDC}$ to give the final DNA-SWCNT concentration of $20 \mathrm{mg} / \mathrm{L}$. These mixtures were kept at $85{ }^{\circ} \mathrm{C}$ for 30 min to displace the DNA with SDC. ${ }^{35}$ The displaced DNA and free SDC were separated from SDC-SWCNTs using $100 \mathrm{kDa}$ Amicon centrifuge filters (one-time filtration). The DNA-displaced SDC-SWCNTs pellet was resuspended in $100 \mathrm{mM} \mathrm{NaCl}$ to reach the final concentration of $20 \mathrm{mg} / \mathrm{L}$, and the final suspension was used for AFM imaging.

Quantification of DNA: To quantify the amount of DNA on the SWCNTs, the mixture of the displaced DNA and free SDC (i.e. the flow-through from the previous $100 \mathrm{kDa}$ filtration) was filtered two times using a $3 \mathrm{kDa}$ Amicon centrifuge filter to separate the DNA from SDC. The DNA remained in the filter and was resuspended in $100 \mathrm{mM} \mathrm{NaCl}$. The weights of the DNA and SWCNTs (i.e. the weight of DNA-displaced SDC-SWCNTs from the previous step) were calculated by the extinction coefficients of $A_{260}=0.027^{60}$ and $A_{910}=0.02554^{61} \mathrm{~L} \cdot \mathrm{mg}^{-1} \cdot \mathrm{cm}^{-1}$, respectively.

Atomic Force Microscopy: Similar to previous studies, ${ }^{63}$ the length distribution of the DNASWCNT and DNA-displaced SDC-SWCNT samples was measured using atomic force microscopy. Free DNA was removed using a $100 \mathrm{kDa}$ Amicon centrifuge filter (Millipore). A stock solution of DNA-SWCNTs or DNA-displaced SDC-SWCNTs at $20 \mathrm{mg} / \mathrm{L}$ was deposited on AP-mica for 4 min before rinsing with $10 \mathrm{~mL}$ of DI water and blowing dry with argon gas. APmica was produced by treating freshly-cleaved mica with aminopropyltriethoxysilane (AP) via the vapor deposition method. Additionally, the stock solution of DNA-displaced SDC-SWCNTs was diluted to $10 \mathrm{mg} / \mathrm{L}$ and $200 \mu \mathrm{L}$ of the sample was spin-coated (Brewer Science CEE-200) onto a cleaned silicon wafer at 2,000 rpm. Excess surfactant was removed from the substrate using DI water. The wafer was pre-cleaned by being placed in an ultrasonic bath (Fisher Scientific 1.9L) in a 50:50 solution of pure ethanol (Sigma-Aldrich) and acetone (Sigma-Aldrich) for 10 minutes 
before being rinsed and bath sonicated for an additional 10 minutes in DI water. An AsylumMFP-3D-BIO AFM with Olympus AC240TS probe was used to image in AC mode. The data was captured with $2.93 \mathrm{~nm} / \mathrm{pixel}$ xy resolution and $15.63 \mathrm{pm}$ z resolution.

Statistical Analysis: Statistical measurements and analyses were performed in OriginPro 2016 using two-sample t-tests under the null hypothesis. Image analysis was performed using Image J software. 


\section{ASSOCIATED CONTENT}

\section{Acknowledgment}

This work was supported by the RI-INBRE Pilot Research Proposal Development Award and Early Career Development Award Grant \# P20GM103430 from the National Institute of General Medical Sciences of the National Institutes of Health, the Rhode Island Foundation Medical Research Fund, and the URI College of Engineering. We thank P. V. Jena for assistance in data analysis and acknowledge M. Brendel and Y. Romin at the imaging core facilities at Memorial Sloan Kettering Cancer Center for AFM imaging.

\section{Corresponding Author}

*E-mail: roxbury@uri.edu.

\section{Author Contributions}

The manuscript was written through contributions of all authors. All authors have given approval to the final version of the manuscript.

\section{Notes}

The authors declare no competing financial interest.

Supporting Information. Additional figures and analysis are found in the supporting information.

This material is freely available on the website, http://pubs.acs.org. 


\section{References}

1. Moore, V. C.; Strano, M. S.; Haroz, E. H.; Hauge, R. H.; Smalley, R. E.; Schmidt, J.; Talmon, Y., Individually Suspended Single-Walled Carbon Nanotubes in Various Surfactants. Nano Letters 2003, 3 (10), 1379-1382.

2. $\quad$ Shi Kam, N. W.; Jessop, T. C.; Wender, P. A.; Dai, H., Nanotube Molecular Transporters: Internalization of Carbon Nanotube-Protein Conjugates into Mammalian Cells. Journal of the American Chemical Society 2004, 126 (22), 6850-6851.

3. Shim, M.; Shi Kam, N. W.; Chen, R. J.; Li, Y.; Dai, H., Functionalization of Carbon Nanotubes for Biocompatibility and Biomolecular Recognition. Nano Letters 2002, 2 (4), 285288.

4. Zheng, M.; Jagota, A.; Semke, E. D.; Diner, B. A.; McLean, R. S.; Lustig, S. R.; Richardson, R. E.; Tassi, N. G., DNA-assisted Dispersion and Separation of Carbon Nanotubes. Nature Materials 2003, 2 (5), 338.

5. $\quad$ Coleman, J. N.; Khan, U.; Gun'ko, Y. K., Mechanical Reinforcement of Polymers using Carbon Nanotubes. Advanced Materials 2006, 18 (6), 689-706.

6. Zhan, G.-D.; Kuntz, J. D.; Wan, J.; Mukherjee, A. K., Single-Wall Carbon Nanotubes as Attractive Toughening Agents in Alumina-based Nanocomposites. Nature Materials 2003, 2 (1), 38 .

7. Kashiwagi, T.; Du, F.; Douglas, J. F.; Winey, K. I.; Harris Jr, R. H.; Shields, J. R., Nanoparticle Networks Reduce the Flammability of Polymer Nanocomposites. Nature Materials 2005, 4 (12), 928.

8. Byrne, M. T.; Gun'ko, Y. K., Recent Advances in Research on Carbon Nanotube-Polymer Composites. Advanced Materials 2010, 22 (15), 1672-1688.

9. Liu, Z.; Cai, W.; He, L.; Nakayama, N.; Chen, K.; Sun, X.; Chen, X.; Dai, H., In vivo Biodistribution and Highly Efficient Tumour Targeting of Carbon Nanotubes in Mice. Nature Nanotechnology 2007, 2 (1), 47.

10. Mulvey, J. J.; Villa, C. H.; McDevitt, M. R.; Escorcia, F. E.; Casey, E.; Scheinberg, D. A., Self-Assembly of Carbon Nanotubes and Antibodies on Tumours for Targeted Amplified Delivery. Nature Nanotechnology 2013, 8 (10), 763.

11. Meng, L.; Zhang, X.; Lu, Q.; Fei, Z.; Dyson, P. J., Single Walled Carbon Nanotubes as Drug Delivery Vehicles: Targeting Doxorubicin to Tumors. Biomaterials 2012, 33 (6), 1689-1698.

12. Williams, R. M.; Lee, C.; Galassi, T. V.; Harvey, J. D.; Leicher, R.; Sirenko, M.; Dorso, M. A.; Shah, J.; Olvera, N.; Dao, F., Noninvasive Ovarian Cancer Biomarker Detection via an Optical Nanosensor Implant. Science Advances 2018, 4 (4), eaaq1090.

13. Jena, P. V.; Roxbury, D.; Galassi, T. V.; Akkari, L.; Horoszko, C. P.; Iaea, D. B.; Budhathoki-Uprety, J.; Pipalia, N.; Haka, A. S.; Harvey, J. D., A Carbon Nanotube Optical Reporter Maps Endolysosomal Lipid Flux. ACS Nano 2017, 11 (11), 10689-10703.

14. Landry, M. P.; Ando, H.; Chen, A. Y.; Cao, J.; Kottadiel, V. I.; Chio, L.; Yang, D.; Dong, J.; Lu, T. K.; Strano, M. S., Single-Molecule Detection of Protein Efflux from Microorganisms Using Fluorescent Single-Walled Carbon Nanotube Sensor Arrays. Nature Nanotechnology 2017, $12(4), 368$.

15. Liang, C.; Diao, S.; Wang, C.; Gong, H.; Liu, T.; Hong, G.; Shi, X.; Dai, H.; Liu, Z., Tumor Metastasis Inhibition by Imaging-Guided Photothermal Therapy with Single-Walled Carbon Nanotubes. Advanced Materials 2014, 26 (32), 5646-5652. 
16. Godin, A. G.; Varela, J. A.; Gao,Z.; Danné, N.; Dupuis, J.P.; Lounis, B.; Groc, L.; Cognet, L., Single-Nanotube Tracking Reveals the Nanoscale Organization of the Extracellular Space in the Live Brain. Nature Nanotechnology 2017, 12 (3), 238.

17. Kruss, S.; Salem, D. P.; Vuković, L.; Lima, B.; Vander Ende, E.; Boyden, E. S.; Strano, M. S., High-Resolution Imaging of Cellular Dopamine Efflux Using a Fluorescent Nanosensor Array. Proceedings of the National Academy of Sciences 2017, 114 (8), 1789-1794.

18. Fakhri, N.; Wessel, A. D.; Willms, C.; Pasquali, M.; Klopfenstein, D. R.; MacKintosh, F. C.; Schmidt, C. F., High-Resolution Mapping of Intracellular Fluctuations using Carbon Nanotubes. Science 2014, 344 (6187), 1031-1035.

19. O'connell, M. J.; Bachilo, S. M.; Huffman, C. B.; Moore, V. C.; Strano, M. S.; Haroz, E. H.; Rialon, K. L.; Boul, P. J.; Noon, W. H.; Kittrell, C., Band Gap Fluorescence from Individual Single-Walled Carbon Nanotubes. Science 2002, 297 (5581), 593-596.

20. Jena, P. V.; Safaee, M. M.; Heller, D. A.; Roxbury, D., DNA-Carbon Nanotube Complexation Affinity and Photoluminescence Modulation Are Independent. ACS applied Materials \& Interfaces 2017, 9 (25), 21397-21405.

21. Liu, Z.; Tabakman, S. M.; Chen, Z.; Dai, H., Preparation of Carbon Nanotube Bioconjugates for Biomedical Applications. Nature Protocols 2009, 4 (9), 1372.

22. Kruss, S.; Landry, M. P.; Vander Ende, E.; Lima, B. M.; Reuel, N. F.; Zhang, J.; Nelson, J.; Mu, B.; Hilmer, A.; Strano, M., Neurotransmitter Detection using Corona Phase Molecular Recognition on Fluorescent Single-Walled Carbon Nanotube Sensors. Journal of the American Chemical Society 2014, 136 (2), 713-724.

23. Hashida, Y.; Tanaka, H.; Zhou, S.; Kawakami, S.; Yamashita, F.; Murakami, T.; Umeyama, T.; Imahori, H.; Hashida, M., Photothermal Ablation of Tumor Cells using a SingleWalled Carbon Nanotube-Peptide Composite. Journal of Controlled Release 2014, 173, 59-66.

24. Heller, D. A.; Pratt, G. W.; Zhang, J.; Nair, N.; Hansborough, A. J.; Boghossian, A. A.; Reuel, N. F.; Barone, P. W.; Strano, M. S., Peptide Secondary Structure Modulates Single-Walled Carbon Nanotube Fluorescence as a Chaperone Sensor for Nitroaromatics. Proceedings of the National Academy of Sciences 2011.

25. Chen, R. J.; Zhang, Y.; Wang, D.; Dai, H., Noncovalent Sidewall Functionalization of Single-Walled Carbon Nanotubes for Protein Immobilization. Journal of the American Chemical Society 2001, 123 (16), 3838-3839.

26. Antonucci, A.; Kupis-Rozmysłowicz, J.; Boghossian, A. A., Noncovalent Protein and Peptide Functionalization of Single-Walled Carbon Nanotubes for Biodelivery and Optical Sensing Applications. ACS Applied Materials \& Interfaces 2017, 9 (13), 11321-11331.

27. Welsher, K.; Liu, Z.; Sherlock, S. P.; Robinson, J. T.; Chen, Z.; Daranciang, D.; Dai, H., A Route to Brightly Fluorescent Carbon Nanotubes for Near-Infrared Imaging in Mice. Nature Nanotechnology 2009, 4 (11), 773.

28. $\quad$ Bisker, G.; Dong, J.; Park, H. D.; Iverson, N. M.; Ahn, J.; Nelson, J. T.; Landry, M. P.; Kruss, S.; Strano, M. S., Protein-Targeted Corona Phase Molecular Recognition. Nature Communications 2016, 7, 10241 .

29. Hong, G.; Diao, S.; Antaris, A. L.; Dai, H., Carbon Nanomaterials for Biological Imaging and Nanomedicinal Therapy. Chemical Reviews 2015, 115 (19), 10816-10906.

30. Heller, D. A.; Mayrhofer, R. M.; Baik, S.; Grinkova, Y. V.; Usrey, M. L.; Strano, M. S., Concomitant Length and Diameter Separation of Single-Walled Carbon Nanotubes. Journal of the American Chemical Society 2004, 126 (44), 14567-14573. 
31. Tu, X.; Manohar, S.; Jagota, A.; Zheng, M., DNA Sequence Motifs for Structure-Specific Recognition and Separation of Carbon Nanotubes. Nature 2009, 460 (7252), 250.

32. Ao, G.; Streit, J. K.; Fagan, J. A.; Zheng, M., Differentiating Left-and Right-Handed Carbon Nanotubes by DNA. Journal of the American Chemical Society 2016, 138 (51), 1667716685.

33. Roxbury, D.; Mittal, J.; Jagota, A., Molecular-Basis of Single-Walled Carbon Nanotube Recognition by Single-Stranded DNA. Nano Letters 2012, 12 (3), 1464-1469.

34. Campbell, J. F.; Tessmer, I.; Thorp, H. H.; Erie, D. A., Atomic Force Microscopy Studies of DNA-Wrapped Carbon Nanotube Structure and Binding to Quantum Dots. Journal of the American Chemical Society 2008, 130 (32), 10648-10655.

35. Roxbury, D.; Tu, X.; Zheng, M.; Jagota, A., Recognition Ability of DNA for Carbon Nanotubes Correlates with their Binding Affinity. Langmuir 2011, 27 (13), 8282-8293.

36. Dong, J.; Salem, D. P.; Sun, J. H.; Strano, M. S., Analysis of Multiplexed Nanosensor Arrays Based on Near-Infrared Fluorescent Single-Walled Carbon Nanotubes. ACS nano 2018, 12 (4), 3769-3779.

37. Budhathoki-Uprety, J.; Langenbacher, R. E.; Jena, P. V.; Roxbury, D.; Heller, D. A., A Carbon Nanotube Optical Sensor Reports Nuclear Entry via a Noncanonical Pathway. ACS nano 2017, 11 (4), 3875-3882.

38. Harvey, J. D.; Jena, P. V.; Baker, H. A.; Zerze, G. H.; Williams, R. M.; Galassi, T. V.; Roxbury, D.; Mittal, J.; Heller, D. A., A Carbon Nanotube Reporter of microRNA Hybridization Events In Vivo. Nature Biomedical Engineering 2017, 1 (4), 0041.

39. Cherukuri, T. K.; Tsyboulski, D. A.; Weisman, R. B., Length- and Defect-Dependent Fluorescence Efficiencies of Individual Single-Walled Carbon Nanotubes. ACS Nano 2012, 6 (1), 843-850.

40. Galassi, T. V.; Jena, P. V.; Shah, J.; Ao, G.; Molitor, E.; Bram, Y.; Frankel, A.; Park, J.; Jessurun, J.; Ory, D. S.; Haimovitz-Friedman, A.; Roxbury, D.; Mittal, J.; Zheng, M.; Schwartz, R. E.; Heller, D. A., An Optical Nanoreporter of Endolysosomal Lipid Accumulation Reveals Enduring Effects of Diet on Hepatic Macrophages In Vivo. Science Translational Medicine 2018, 10 (461).

41. Becker, M. L.; Fagan, J. A.; Gallant, N. D.; Bauer, B. J.; Bajpai, V.; Hobbie, E. K.; Lacerda, S. H.; Migler, K. B.; Jakupciak, J. P., Length-Dependent Uptake of DNA-Wrapped Single-Walled Carbon Nanotubes. Advanced Materials 2007, 19 (7), 939-945.

42. Jin, H.; Heller, D. A.; Sharma, R.; Strano, M. S., Size-Dependent Cellular Uptake and Expulsion of Single-Walled Carbon Nanotubes: Single Particle Tracking and a Generic Uptake Model for Nanoparticles. Acs Nano 2009, 3 (1), 149-158.

43. Khripin, C. Y.; Arnold-Medabalimi, N.; Zheng, M., Molecular-Crowding-Induced Clustering of DNA-Wrapped Carbon Nanotubes for Facile Length Fractionation. ACS nano 2011, 5 (10), 8258-8266.

44. Han, X.; Li, Y.; Deng, Z., DNA-Wrapped Single Walled Carbon Nanotubes as Rigid Templates for Assembling Linear Gold Nanoparticle Arrays. Advanced Materials 2007, 19 (11), 1518-1522.

45. Fagan, J. A.; Becker, M. L.; Chun, J.; Hobbie, E. K., Length Fractionation of Carbon Nanotubes Using Centrifugation. Advanced Materials 2008, 20 (9), 1609-1613.

46. Asada, Y.; Miyata, Y.; Shiozawa, K.; Ohno, Y.; Kitaura, R.; Mizutani, T.; Shinohara, H., Thin-Film Transistors with Length-Sorted DNA-Wrapped Single-Wall Carbon Nanotubes. The Journal of Physical Chemistry C 2010, 115 (1), 270-273. 
47. Zhang, J.; Boghossian, A. A.; Barone, P. W.; Rwei, A.; Kim, J.-H.; Lin, D.; Heller, D. A.; Hilmer, A. J.; Nair, N.; Reuel, N. F., Single Molecule Detection of Nitric Oxide Enabled by d (AT) 15 DNA Adsorbed to Near Infrared Fluorescent Single-Walled Carbon Nanotubes. Journal of the American Chemical Society 2010, 133 (3), 567-581.

48. Zhou, Z.; Kang, H.; Clarke, M. L.; Lacerda, S. H. D. P.; Zhao, M.; Fagan, J. A.; Shapiro, A.; Nguyen, T.; Hwang, J., Water-Soluble DNA-Wrapped Single-Walled CarbonNanotube/Quantum-Dot Complexes. Small 2009, 5 (19), 2149-2155.

49. Tong, L.; Liu, Y.; Dolash, B. D.; Jung, Y.; Slipchenko, M. N.; Bergstrom, D. E.; Cheng, J.-X., Label-Free Imaging of Semiconducting and Metallic Carbon Nanotubes in Cells and Mice using Transient Absorption Microscopy. Nature Nanotechnology 2012, 7 (1), 56.

50. Lee, A. J.; Wang, X.; Carlson, L. J.; Smyder, J. A.; Loesch, B.; Tu, X.; Zheng, M.; Krauss, T. D., Bright Fluorescence from Individual Single-Walled Carbon Nanotubes. Nano Letters 2011, 11 (4), 1636-1640.

51. Khripin, C. Y.; Tu, X.; Howarter, J.; Fagan, J.; Zheng, M., Concentration Measurement of Length-Fractionated Colloidal Single-Wall Carbon Nanotubes. Analytical Chemistry 2012, 84 (20), 8733-8739.

52. Asada, Y.; Nihey, F.; Ohmori, S.; Shinohara, H.; Saito, T., Diameter-Dependent Performance of Single-Walled Carbon Nanotube Thin-Film Transistors. Advanced Materials 2011, 23 (40), 4631-4635.

53. Hayashida, T.; Umemura, K., Atomic Force Microscopy of DNA-Wrapped Single-Walled Carbon Nanotubes in Aqueous Solution. Colloids and Surfaces B: Biointerfaces 2016, 143, 526531 .

54. Miyauchi, Y.; Matsuda, K.; Yamamoto, Y.; Nakashima, N.; Kanemitsu, Y., LengthDependent Photoluminescence Lifetimes in Single-Walled Carbon Nanotubes. The Journal of Physical Chemistry C 2010, 114 (30), 12905-12908.

55. Huang, X.; McLean, R. S.; Zheng, M., High-Resolution Length Sorting and Purification of DNA-Wrapped Carbon Nanotubes by Size-Exclusion Chromatography. Analytical Chemistry 2005, 77 (19), 6225-6228.

56. Zheng, M.; Jagota, A.; Strano, M. S.; Santos, A. P.; Barone, P.; Chou, S. G.; Diner, B. A.; Dresselhaus, M. S.; Mclean, R. S.; Onoa, G. B., Structure-Based Carbon Nanotube Sorting by Sequence-Dependent DNA Assembly. Science 2003, 302 (5650), 1545-1548.

57. Asada, Y.; Miyata, Y.; Ohno, Y.; Kitaura, R.; Sugai, T.; Mizutani, T.; Shinohara, H., HighPerformance Thin-Film Transistors with DNA-Assisted Solution Processing of Isolated SingleWalled Carbon Nanotubes. Advanced Materials 2010, 22 (24), 2698-2701.

58. Streit, J. K.; Bachilo, S. M.; Naumov, A. V.; Khripin, C.; Zheng, M.; Weisman, R. B., Measuring Single-Walled Carbon Nanotube Length Distributions From Diffusional Trajectories. Acs Nano 2012, 6 (9), 8424-8431.

59. Chiang, I.; Brinson, B.; Huang, A.; Willis, P.; Bronikowski, M.; Margrave, J.; Smalley, R.; Hauge, R., Purification and Characterization of Single-Wall Carbon Nanotubes (SWNTs) Obtained from the Gas-Phase Decomposition of CO (HiPco Process). The Journal of Physical Chemistry B 2001, 105 (35), 8297-8301.

60. Tataurov, A. V.; You, Y.; Owczarzy, R., Predicting Ultraviolet Spectrum of Single Stranded and Double Stranded Deoxyribonucleic Acids. Biophysical Chemistry 2008, 133 (1-3), 66-70. 
61. Roxbury, D.; Jena, P. V.; Williams, R. M.; Enyedi, B.; Niethammer, P.; Marcet, S.; Verhaegen, M.; Blais-Ouellette, S.; Heller, D. A., Hyperspectral Microscopy of Near-Infrared Fluorescence Enables 17-Chirality Carbon Nanotube Imaging. Scientific Reports 2015, 5, 14167.

62. Galassi, T. V.; Jena, P. V.; Shah, J.; Ao, G.; Molitor, E.; Bram, Y.; Frankel, A.; Park, J.; Jessurun, J.; Ory, D. S., An Optical Nanoreporter of Endolysosomal Lipid Accumulation Reveals Enduring Effects of Diet on Hepatic Macrophages In Vivo. Science Translational Medicine 2018, 10 (461), eaar2680.

63. Jena, P. V.; Shamay, Y.; Shah, J.; Roxbury, D.; Paknejad, N.; Heller, D. A., Photoluminescent Carbon Nanotubes Interrogate the Permeability of Multicellular Tumor Spheroids. Carbon 2016, 97, 99-109.

\section{TOC}

Length Distributions of Deposited DNA-SWCNTs

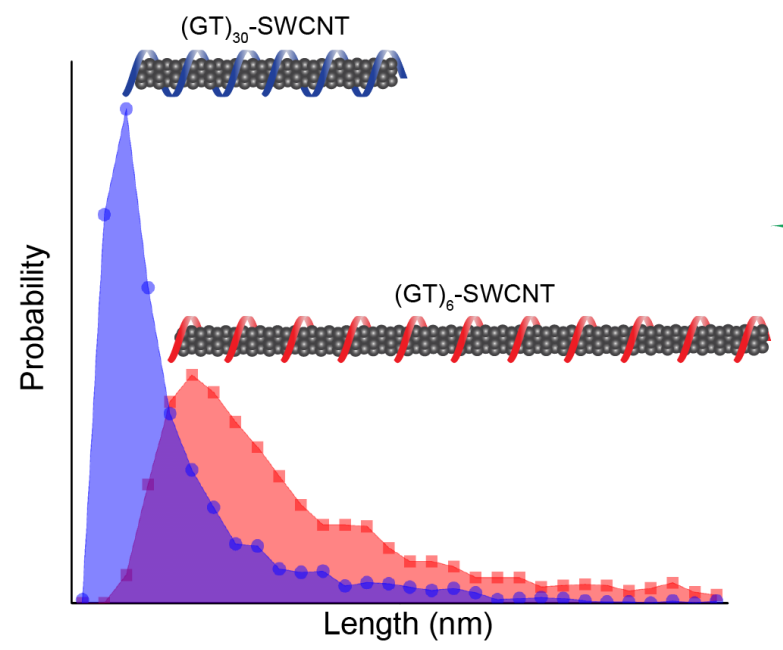

Length Distributions After DNA Displacement

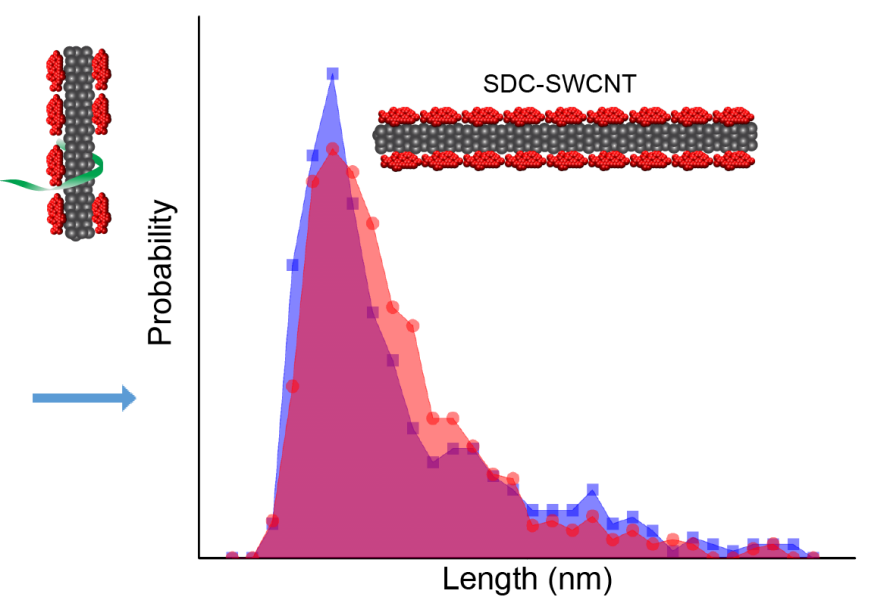

